\title{
Analysis of an idealized counter-current microchannel-based reactor to produce hydrogen- rich syngas from methanol
}

\author{
Daniel Fernández-Galisteo ${ }^{a, *}$, Eduardo Fernández-Tarrazo ${ }^{b}$, \\ Carmen Jiménez ${ }^{a}$, Vadim N. Kurdyumov ${ }^{a}$ \\ a Department of Energy, CIEMAT, Auda. Complutense 40, 28040, Madrid, Spain \\ ${ }^{\mathrm{b}}$ Dept. Ingeniería Térmica y de Fluidos, Universidad Carlos III de Madrid, 28911, Leganés, Spain
}

H I G H L I G H T S

-We present a numerical model for portable hydrogen production for fuel cells.

- Methanol thermal partial oxidation in counter-current channels is investigated.

- Maximum hydrogen yield of $60 \%$ at equivalence ratios between 3 and 6 is predicted.

- Gas inflow velocity has small influence on the conversion efficiency of the reactor.

\section{A R T I C L E I N F O}

\section{Article history:}

Received 12 April 2019

Received in revised form

5 July 2019

Accepted 12 July 2019

Available online 8 August 2019

\section{Keywords:}

Micro combustion

Partial oxidation

Narrow-channel approximation

Fuel reforming

Hydrogen

\begin{abstract}
A B S T R A C T
In an effort to investigate the suitability of the concept of portable hydrogen production, we examine numerically the combustion of a very rich methanol-air mixture in a micro-gap assembly consisting of multiple counter-current channels of finite length separated by thin solid conducting walls. Within the mathematical framework of the narrow-channel approximation, the problem can be formulated as a one-dimensional model for a single channel with an extra term representing heat transfer from the hot stream products to the fresh reactants in adjacent channels. We show that the heat recirculation enables superadiabatic temperatures inside the reactor and promotes the oxidation of methanol far beyond the conventional rich limit of flammability. The result is a feasible thermal partial oxidation that produces hydrogen without the need for a catalyst. The paper presents an analysis of the model burner performance with detailed gas-phase kinetics in stationary regimes in terms of operating variables such as the equivalence ratio and the gas inflow velocity, and in terms of physical parameters such as the length of the reformer and the conductivity of the wall material. The idealized microreactor predicts maximum hydrogen yield of the order of $60 \%$ at equivalence ratios between 3 and 6 .
\end{abstract}

๑) 2019 Hydrogen Energy Publications LLC. Published by Elsevier Ltd. All rights reserved.

\footnotetext{
* Corresponding author.

E-mail address: d.galisteo@ciemat.es (D. Fernández-Galisteo).
} 


\section{Introduction}

Hydrogen-based fuel cell technology is increasingly considered as an alternative to conventional electrochemical batteries to power small portable systems (i.e., in the range of 1-100 W) because of the fast startup and the high energy density [1-3]. For example, proton-exchange membrane (PEM) fuel cells provide five times higher energy density than current lithium-ion batteries $(0.2 \mathrm{kWh} / \mathrm{kg})$. The operation of PEM fuel cells requires pure hydrogen, which has to be stored or produced in situ. In order to supply significant amounts of energy, hydrogen has to be stored either as a liquid in cryogenic conditions or as a gas at high pressures. Hydrogen production from reforming of hydrocarbon fuels is a good alternative as several hydrocarbons (methanol, ethanol, ...) can be stored as liquids in ambient conditions, providing very high energy density. As a practical example of an integrated micro system we can mention the microscale power device developed by Pacific Northwest National Labs [4], which is composed of a fuel reformer and a fuel cell. The fuel reformer, that stripped hydrogen from methanol, resulted in the production of $0.1 \mathrm{~W}$ of hydrogen which was used to feed the fuel cell to generate electrical power.

The obtention of large hydrogen conversion rates from hydrocarbons in small-volume reformers requires completion of the chemical process within a short residence time. As shown for freely propagating, adiabatic rich premixed flames [5], this chemical process is limited by the kinetics, in particular by slow reforming reactions. For this reason, catalyst layers [6-11] or heat recirculation [12-16] are frequently employed in order to accelerate these reactions. The three main methods for hydrogen production using hydrocarbons are steam reforming, autothermal reforming and partial oxidation. Most of the prototypes fabricated and tested for microscale hydrogen production make use of the steam reforming with catalyst [6-8], where key aspects of design involve adequate selection of catalyzer [9] as well as reactant transport for an efficient use of the catalyzer $[10,11]$. As steam reforming is an endothermic process, a catalytic combustor is employed in parallel to supply the sufficient amount of heat to sustain the steam reforming. These devices then combine a reformer and a combustor in a single configuration of micro parallel channels. One can simplify the design by taking advantage of the partial oxidation method in a heatrecirculating configuration. Partial oxidation has the disadvantage of lower $\mathrm{H}_{2}$ /CO ratios $(\sim 2: 1)$ compared with steam reforming $(\sim 3: 1)$ but, given that partial oxidation is exothermic, this method avoids the integration of a combustor element that supplies heat for the steam reforming process. Heat recirculation is a well-known concept used for burning mixtures which may not be flammable at standard conditions $[17,18]$. The idea is to extend the rich flammability limit so that oxidation of richer mixtures is feasible. Richer mixtures result in larger concentrations of $\mathrm{H}_{2}$ and $\mathrm{CO}$ (syngas) and smaller concentrations of $\mathrm{H}_{2} \mathrm{O}$ and $\mathrm{CO}_{2}$ in the product stream. Most importantly, heat recirculation avoids the use of catalysts and the associated degradation and poisoning in microchannel-based operating conditions. A possible drawback of this micro-reformer is the deposition of soot on the walls at ultra-rich equivalence ratios.

Several experimental works have demonstrated the feasibility of hydrogen production without catalysts using a heatrecirculating configuration. Some of them use multiple parallel channels with alternating flow directions, similar to the sketch in Fig. 1, and others double-spiral geometries (e.g., Swiss-roll). Within the first group, we can mention the work of Ellzey et al. [12-14], who used four parallel counter-current channels separated by silicon carbide walls. The opposing combustion zones are self-stabilized as reactants are preheated by the product stream in the adjacent channels. The length of the main reactor section was $10 \mathrm{~cm}$, with channel gaps of $4 \mathrm{~mm}$ and separating walls of $1 \mathrm{~mm}$ thickness. The cross-section area was $134.4 \mathrm{~mm}^{2}$. One of the principal features of that design was that stable combustion was obtained for a wide range of flow rates and reactant mixtures. This reactor prototype was investigated with methane, propane and liquid heptane as fuel, with inflow velocities between 37.5 and $300 \mathrm{~cm} / \mathrm{s}$ and equivalence ratios between $\phi=1.8$ and 3.9 (The equivalence ratio $\phi$ is defined as the fuel to air mass ratio divided by the stoichiometric fuel to air mass ratio). The exhaust gas composition had peak $\mathrm{H}_{2}$ mole fractions of $18 \%$ for methane, $16.7 \%$ for propane and $14.5 \%$ for heptane at $\phi=2.5,2.4$ and 2.9 , respectively, for a fixed gas inflow velocity at $125 \mathrm{~cm} / \mathrm{s}$. The authors reported hydrogen yield of $50 \%$ for methane and propane and $40 \%$ for heptane. Within the second group, the Swiss-roll burner stabilizes a single combustion zone in the center of the burner and heat is transferred along the counter-current double-spiral channels. Experiments using propane in a 6-turn Swiss-roll burner reported $\mathrm{H}_{2}$ mole fraction in the reformate gas of $18 \%$ when the inflow velocity was fixed to $200 \mathrm{~cm} / \mathrm{s}$ and the equivalence ratio to $\phi=$ $3[15,16]$.

Combustion in inert porous media to produce hydrogen is another solution based on preheating of the reactants [19-24]. Differently to the counter-current configuration, the combustion front in this case is not steady and propagates along the porous reactor material. To maintain the combustion front inside the reactor, additional techniques such as periodic restarting or reversal of the flow are required. With the addition of a second porous layer, however, the porous media reactor can support stationary combustion [21]. The most compact porous reactor for hydrogen production was investigated by Pedersen-Mjaanes et al. [21] with different fuels (methanol, methane, octane and petrol) and different porous materials (foams and beads). The reactor was $25 \mathrm{~cm}$ in length with an internal diameter of $3 \mathrm{~cm}$. The authors reported $\mathrm{H}_{2}$ mole fraction in the exhaust gas of $28 \%$ for methanol, $13 \%$ for methane and $11 \%$ for octane at $\phi=4.6,1.8$ and 2.1 , respectively. Methanol combustion was sustained for $\phi=9.3$, well beyond the conventional flammability limit of $\phi=4$.1. Notice that, for the case of methanol, the equivalence ratio is defined as $\phi=2 \mathrm{X}_{\mathrm{CH}_{3} \mathrm{OH}, \mathrm{u}} / 3 \mathrm{X}_{\mathrm{O}_{2}, \mathrm{u}}$, where $\mathrm{X}_{\mathrm{CH}_{3} \mathrm{OH}, \mathrm{u}}$ and $\mathrm{X}_{\mathrm{O}_{2}, \mathrm{u}}$ are the mole fractions of the fuel and oxidant in the fresh mixture.

Numerical modeling is a convenient tool to investigate combustion in small-scale reformers. Combustion at ultrarich conditions requires consideration of detailed chemical kinetics [20] because the final product composition is essentially 


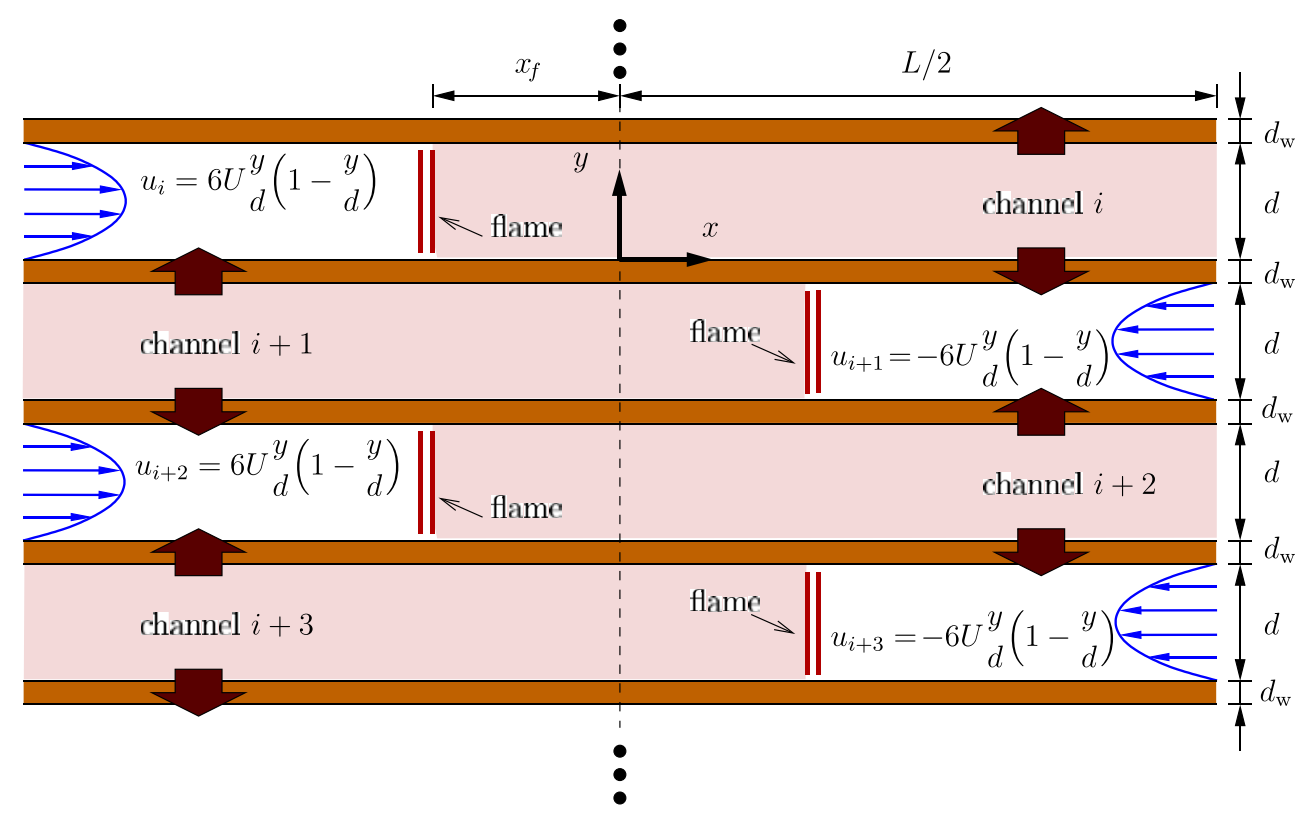

Fig. 1 - Sketch of the array of counter-current narrow channels and the coordinate system centered in the lower wall of channel $i$. In the figure, $L$ is the length of the channels, $d$ is the distance between the internal surfaces of the walls, $d_{w}$ is the thickness of the solid conducting walls, and $x_{f}$ is half the distance between the opposed symmetric flames. Adapted from Ref. [28].

controlled by the kinetics. For small-scale reformers in particular, the kinetics becomes a limiting factor due to the small residence time of the products stream in the reactor. In the literature, numerical simulations with detailed chemical kinetics have been limited to one-dimensional models for porous burners $[20,22,23,25]$. For parallel counter-current channels the simulations are scarce. We can only cite the two-dimensional work presented by Ellzey et al. [26,27].

In this paper we analyze the partial oxidation of methanol in counter-current narrow channels with the use of detailed gas-phase chemical kinetics and an accurate determination of the thermochemical and transport properties. Because of the periodicity, the problem can be reduced to the analysis of a single channel. Further mathematical simplification to a onedimensional problem is justified herein in the framework of the narrow-channel approximation. In this way, the computational cost is diminished and a parametric study is viable. We investigate in detail the evolution of the temperature and the major species profiles along the channel reactor and the effect of four parameters (the equivalence ratio, the gas inflow velocity, the length of the reactor, and the conductivity of the solid wall material) on the hydrogen conversion rate.

\section{General formulation}

Consider very rich methanol-air oxidation in an infinite array of parallel counter-current narrow planar channels of width $d$ and length $L$, separated by solid conducting walls of thickness $d_{\mathrm{w}}$. In Fig. 1 we illustrate the reactor design. In this configuration each channel can be treated as thermally isolated from the exterior because the infinite number of channels in the $y$-direction makes the problem periodic. Notice that, in experiments, when the number $n$ of channels is sufficiently large, the heat losses experienced by the central channels will be negligible while the outer channels losses can be minimized if special arrangements are done in the experimental setup. For $n \sim 1$, heat losses may play a significant role, but this case is out of the scope of the present work.

The gas mixture is introduced through the channels at an initial temperature $T_{u}=343 \mathrm{~K}$ (higher than the standard temperature to prevent condensation of the vaporized methanol) and velocity $U_{u}$.

Assuming that the channel width $d$ is much smaller than the flame thickness $\left(d \ll \delta_{T}\right)$, defined as $\delta_{T}=D_{T} / S_{L} \sim 0.25 \mathrm{~mm}$, with $D_{T}=\lambda_{g} /\left(\rho c_{p}\right) \sim 2 \cdot 10^{-5} \mathrm{~m}^{2} / \mathrm{s}$ and $S_{L} \sim 8 \mathrm{~cm} / \mathrm{s}$ being respectively the thermal diffusivity and the propagation velocity of the planar flame (reference magnitudes for $\phi=3$ at standard conditions), the conservation equations for the gas phase are reduced below to a one-dimensional form with flow properties averaged across the channel (narrow-channel approximation or thick flame limit [29-32]). It was demonstrated that this approximation could be extended in some cases beyond its strict limit of validity [31].

In the present study the heat flux through a thin wall is taken to be proportional to the differences of the temperatures at each side of the wall multiplied by the wall thermal conductivity, $\lambda_{\mathrm{w}}$, and divided by its thickness, $d_{\mathrm{w}}$. Assuming equal gas inflow velocity $U_{u}$ in all the channels (so that flames are stabilized at symmetric positions $\pm x_{f}$, see Refs. [28,33-35]), periodicity allows to reduce the analysis to a single channel $i$ by integrating the following steady gas-phase governing equations: 
$\rho U=\rho_{u} U_{u}=$ const.

$\rho c_{p} U \frac{d T}{d x}=\frac{d}{d x}\left(\lambda_{g} \frac{d T}{d x}\right)-\rho \sum_{k=1}^{N} c_{p, k} Y_{k} V_{k} \frac{d T}{d x}-\sum_{k=1}^{N} \dot{\omega}_{k} h_{k} W_{k}$

$-\frac{2 \lambda_{\mathrm{w}}}{d d_{\mathrm{w}}}[\mathrm{T}(x)-\mathrm{T}(-x)]$

$\rho U \frac{d Y_{k}}{d x}=-\frac{d}{d x}\left(\rho Y_{k} V_{k}\right)+\dot{\omega}_{k} W_{k}, \quad k=1,2, \ldots, N$

$\rho=\frac{p_{\mathrm{atm}} \overline{\mathrm{W}}}{\mathrm{RT}}$,

with the corresponding flux boundary conditions at the left and right ends given by

$x=-L / 2:\left\{\begin{array}{c}\rho_{u} U_{u} h_{u}=\rho U h-\lambda_{g} \frac{d T}{d x}+\sum_{k=1}^{N} \rho Y_{k} V_{k} h_{k}, \\ \rho_{u} U_{u} Y_{k_{u}}=\rho U Y_{k}+\rho Y_{k} V_{k},\end{array}\right.$

$x=L / 2: \quad \frac{d T}{d x}=0, \frac{d Y_{k}}{d x}=0$,

for $k=1,2, \ldots, N$, where $h=\sum_{k=1}^{N} h_{k}(T) Y_{k}$ and $h_{u}=\sum_{k=1}^{N} h_{k}\left(T_{u}\right) Y_{k_{u}}$ are the specific enthalpy of the mixture at the inlet of the reactor and at the fresh unburned mixture, respectively.

This one-dimensional formulation is identical to that describing the propagation of a planar flame [36], with $\rho U$ being the eigenvalue of the problem. Here, however, $U$ is the flow velocity averaged across the channel width,

$U(x)=\frac{1}{d} \int_{0}^{d} u(x, y) d y$,

with $u(x, y)=6 U(y / d)(1-y / d)$ the prescribed Poiseuille form of the axial velocity distribution. Hydrodynamic pressure deviation from the ambient atmospheric pressure, $p^{\prime}=p-p_{\text {atm }}$, is not required in the framework of the narrow-channel approximation but it can be calculated a posteriori by integrating the equation $d p^{\prime} / d x=-12 \mu U(x) / d^{2}$, with $\mu$ the dynamic viscosity of the gas mixture.

In the above equations $Y_{k}$ is the mass fraction of the $k^{\text {th }}$ species, $p_{\text {atm }}$ is the ambient (atmospheric) pressure, $\rho$ is the gas density, $c_{p}$ is the specific heat of the mixture at constant pressure, $\lambda_{g}$ is the thermal conductivity of the gas, $\dot{\omega}_{k}$ is the molar rate of production of the $k^{\text {th }}$ species per unit volume and it is specified through the elementary reactions of the kinetic mechanism introduced in section Chemical kinetics, $h_{k}$ is the specific enthalpy of the $k^{\text {th }}$ species, $V_{k}$ is the diffusion velocity of the $k^{\text {th }}$ species (calculated with the multicomponent diffusion model [37]), $W_{k}$ is the molecular weight of the $k^{\text {th }}$ species, $\mathrm{W}$ is the mean molecular weight, $\mathrm{R}$ is the universal gas constant, and $\mathrm{N}$ stands for the total number of chemical species.

The last term on the right-hand side of Eq. (2) represents the effect of heat recirculation. Note that due to symmetry with respect to $x=0$ between adjacent channels $i$ and $i+1$, this term evaluates the temperature difference at positions $x$ and $-x$. The parameter $b=2 \lambda_{\mathrm{w}} /\left(d d_{\mathrm{w}}\right)$ stands for the reduced conductivity factor of the wall. For a microburner with $d=4$ $\mathrm{mm}$ and $d_{\mathrm{w}}=1 \mathrm{~mm}$, the order of magnitude of $b$ lies typically between $10^{5} \mathrm{~W} /\left(\mathrm{m}^{3} \mathrm{~K}\right)$ for less conductive materials as quartz to $10^{7} \mathrm{~W} /\left(\mathrm{m}^{3} \mathrm{~K}\right)$ for more conductive materials as silicon carbide [12-14]. In the present study we will use two different values of the conductivity factor, e.g., $b=10^{5} \mathrm{~W} /\left(\mathrm{m}^{3} \mathrm{~K}\right)$ and $b=$ $10^{6} \mathrm{~W} /\left(\mathrm{m}^{3} \mathrm{~K}\right)$. For thin separating walls, not very highly conducting materials and small channel widths (parameters associated typically to microreactors), the analysis of Schoegl et al. [28] supports the narrow-channel approximation.

\section{Chemical kinetics}

The partial oxidation process has been modeled with the detailed San Diego mechanism that involves $N=50$ reactive species and 247 elementary reactions; the individual reaction rates, needed to obtain $\dot{\omega}_{k}$, as functions of the species concentration and temperature are specified in Ref. [38] in standard chemkin format. We will not detail here a listing of all reactions as they can readily be found in Ref. [38]. The mechanism was recently tested for a broad range of conditions in premixed, non-premixed and auto-ignition problems for methanol combustion [39]. To illustrate this, we have plotted in Fig. 2 the laminar flame velocity variation with the equivalence ratio for methanol-air mixtures at two different initial temperatures. It shows that detailed computations of freely propagating flames are in good agreement with experimental measurements. No experimental data are available for equivalence ratios larger than $\phi>1.4$ so that reasonable caution should be exerted in this work. We mark also in Fig. 2 the conventional flammability limits [40].

Note that Fig. 2 shows a change of behavior in the flame velocity variation close to $\phi \approx 2$. Above this value, the flame structure is different from that found in lean or stoichiometric mixtures [41]. $\mathrm{O}_{2}$ is completely consumed in the reaction zone

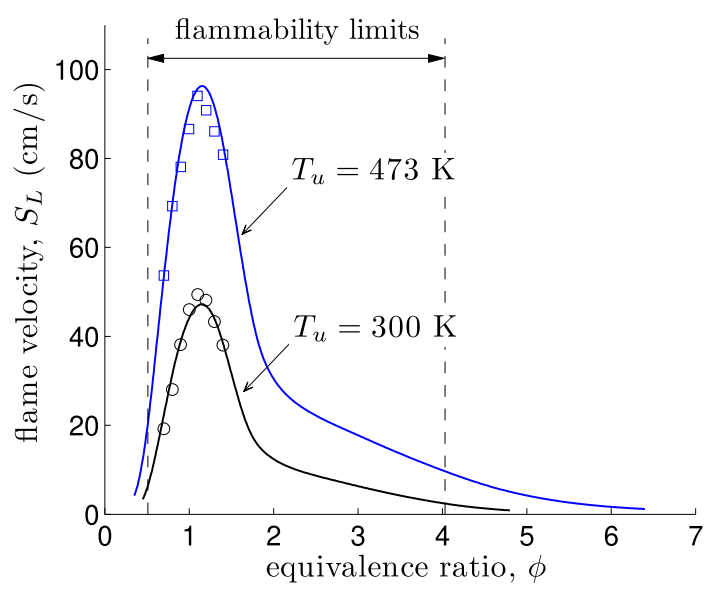

Fig. 2 - Variation of the laminar flame velocity with the equivalence ratio for a methanol-air mixture at atmospheric pressure and different initial temperatures. Solid curves: computed with the detailed San Diego mechanism [38]; symbols: experimental measurements ( $\bigcirc$ Saeed and Stone [42]; $\square$ Zhang et al. [43]). Conventional flammability limits obtained from Ref. [40] (rich limit measured at $\left.60{ }^{\circ} \mathrm{C}\right)$. 
and fuel leaks downstream, where it is consumed by slow endothermic reforming reactions [5] (e.g., $\mathrm{CH}_{3} \mathrm{OH}+\mathrm{H}_{2} \mathrm{O} \rightarrow$ $\mathrm{CO}_{2}+3 \mathrm{H}_{2}$ ) followed by water-gas-shift reactions (e.g., $\mathrm{CO}+\mathrm{H}_{2} \mathrm{O} \rightarrow \mathrm{CO}_{2}+\mathrm{H}_{2}$ ) that bring the species concentrations to equilibrium values. Products from freely-propagating flames at high equivalence ratios require extremely large residence times (tens of seconds) to reach the equilibrium concentrations. As will be shown below, heat recirculation reduces the required residence times for hydrogen conversion in the present microburners to more practical values (miliseconds).

\section{Inlet/outlet boundary conditions for the reactor numerical model}

Inlet/outlet boundary conditions for flow reactors are based on the idea that there are no chemical reactions outside the finite length of the reactor [44]. The flux boundary conditions Eqs. (5) and (6) employed in the present problem were obtained following this assumption. This assumption is legitimate at the reactor inlet due to the low temperature of the mixture (negligible chemical reactions), but might be questionable at the outlet (in the region of hot products). To check the validity of Eqs. (5) and (6), we conducted a numerical experiment: we assumed a new, infinite computational domain for the channel i, comprising three zones, as shown in Fig. 3. Zone 2 is the heat-recirculating channel itself and zones 1 and 3 correspond to two semi-infinite sections outside the channel, where heat recirculation is excluded. In this new computational domain, inlet/outlet boundary conditions for channel $i$ can be imposed in the standard way as $T=T_{u}$ and $\mathrm{Y}_{k}=\mathrm{Y}_{k_{u}}$ at $\mathrm{x} \rightarrow-\infty$ and $\mathrm{dT} / \mathrm{dx}=\mathrm{d} \mathrm{Y}_{\mathrm{k}} / \mathrm{dx}=0$ at $\mathrm{x} \rightarrow \infty$, for $k=1$, $\ldots, N$.

In Fig. 4 we compare the temperature and the molar fraction profiles of $\mathrm{CH}_{3} \mathrm{OH}, \mathrm{O}_{2}, \mathrm{H}_{2}$ and $\mathrm{CO}$ obtained by solving the problem in the infinite domain consisting of three zones (dashed curves) with those obtained by solving the problem inside the reactor only using the flux boundary conditions Eqs. (5) and (6) (solid curves). The comparison is made for mixtures with $\phi=1$, 3 and 5. As can be seen, differences inside the reactor are insignificant. Negligible deviations are found only very close to the exit due to the zero-gradient condition in Eq. (6).

It is, however, noteworthy that the temperature and the species concentrations can differ in some circumstances between the exit of the reactor and the conditions found sufficiently far downstream (e.g., in an storage tank). The finite rate chemical kinetics can lead to non-equilibrium concentrations and temperature at the outlet of the reactor, depending on the reactor length. In particular, for $\phi=1$, Fig. 4a) shows that the outflow gas temperature is below the adiabatic temperature (marked with dot-dashed line). At the same time, Fig. 4b) shows that species such as $\mathrm{H}_{2}$ and $\mathrm{CO}$ are in larger concentrations than those predicted by the chemical equilibrium state. Because of the finite size of the reactor, and a short residence time, these species have not been completely oxidized at the outlet. $\mathrm{H}_{2}$ and $\mathrm{CO}$ are oxidized outside (zone 3) until they reach the equilibrium composition and the adiabatic temperature. For $\phi=5$, however, the temperature and the species concentrations of the exhaust gas are held constant outside the reactor. The rate of reforming reactions becomes very slow at the low gas temperature in the outlet (900 K) so chemical reactions are practically frozen. Methanol leakage occurs in the reaction zone and small concentrations appear in the exhaust gas. The composition reaches a metastable state that does not necessarily correspond with the equilibrium state. Similarly, results for $\phi=3$ show a frozen exhaust gas composition in zone 3 .

The above findings suggest that calculations assuming a finite reactor with boundary conditions Eqs. (5) and (6) are adequate to correctly predict the concentrations of the species in the exhaust gas of the reactor.

\section{Equilibrium composition}

Chemical equilibrium calculations assume maximum entropy conditions, which in practice require infinite residence time for all the chemical reactions to be completed. In order to evaluate the efficiency of the hydrogen production process in finite-residence-time reactors, we will use thermodynamic equilibrium calculations as a reference level $[13,24]$. In this paper, the equilibrium state composition was obtained at constant pressure and enthalpy using the NASA's computer program CEA (Chemical Equilibrium with Applications) [45].

In Fig. 5 we plot the calculated equilibrium compositions as a function of the equivalence ratio at standard conditions. The molar fractions measured in the burned products of freelypropagating premixed flame are shown with symbols for $\phi=1,2$ and 3. In the premixed-flame calculations the equilibrium composition was reached for residence times of $10 \mathrm{~ms}$ for $\phi=1,100 \mathrm{~ms}$ for $\phi=2$ and more than $20 \mathrm{~s}$ for $\phi=3$. The computation for $\phi=3$ required a very long domain and yet results for some species were out of equilibrium (this is the case of $\mathrm{H}_{2}$ and $\mathrm{H}_{2} \mathrm{O}$ concentrations in Fig. 5). It may be noted in Fig. 5 that unburned $\mathrm{CH}_{4}$ and soot precursor $\mathrm{C}_{2} \mathrm{H}_{6}$ appear at very rich conditions.

\section{Numerical treatment}

Detailed chemistry and transport computations were performed with the one-dimensional code LFLAM, which is based

\begin{tabular}{c|ccc}
\hline $\begin{array}{c}\text { zone 1 } \\
\text { (without h.r.) }\end{array}$ & $\stackrel{\text { flow }}{\longrightarrow}$ & $\begin{array}{c}\text { zone 2 } \\
\text { (with heat recirculation) }\end{array}$ & $\begin{array}{c}\text { zone 3 } \\
\text { (without h.r.) }\end{array}$ \\
\hline$x \rightarrow-\infty \quad x=-L / 2$ & $x=L / 2 \quad x \rightarrow \infty$
\end{tabular}

Fig. 3 - Example of an infinite heat-recirculating channel where the computational domain is divided into 3 zones. Heat recirculation is only permitted through the walls in zone 2, while in zone 1 and 3 the walls are considered as adiabatic. 

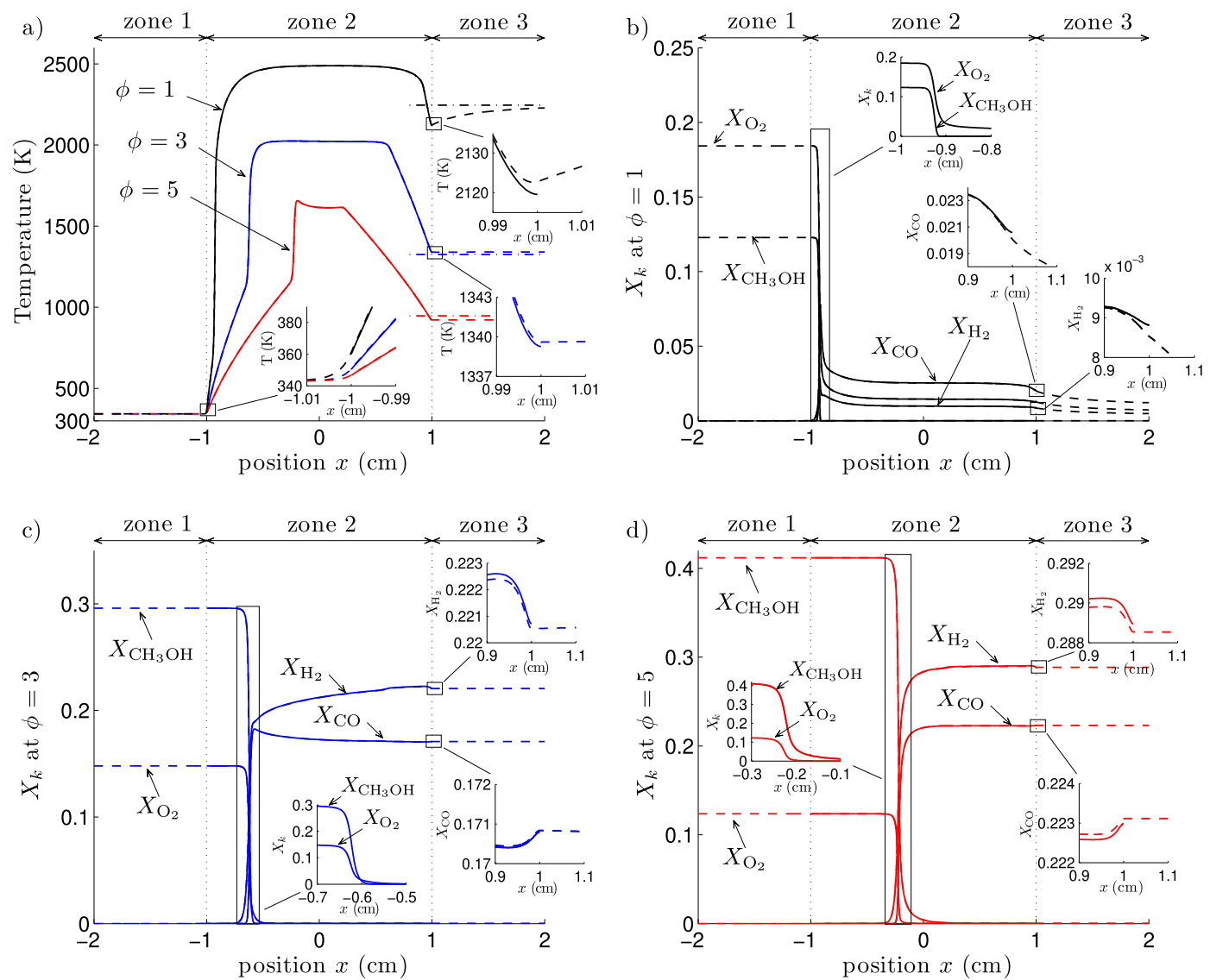

Fig. 4 - Profiles of temperature, methanol, oxygen, hydrogen and carbon monoxide molar fractions along channel $i$ calculated using an infinite three-zone model (dashed curves) and using a finite one-zone model (solid curves). Calculated for $\phi=\{1,3,5\}$, with $U_{u}=100 \mathrm{~cm} / \mathrm{s}, T_{u}=343 \mathrm{~K}, b=4 \cdot 10^{5} \mathrm{~W} /\left(\mathrm{m}^{3} \mathrm{~K}\right)$, and $\mathrm{L}=2 \mathrm{~cm}$. Dot-dashed lines in a) correspond to adiabatic temperatures. The insets show zooms of the inlet, combustion zone and outlet of the reactor.

on the equations described in Ref. [46], adapted here to account for the heat-recirculating problem. The code solves Eqs. (2) -(4) using a finite difference discretization on an adaptative non-uniform grid. Convective terms are discretized with first-

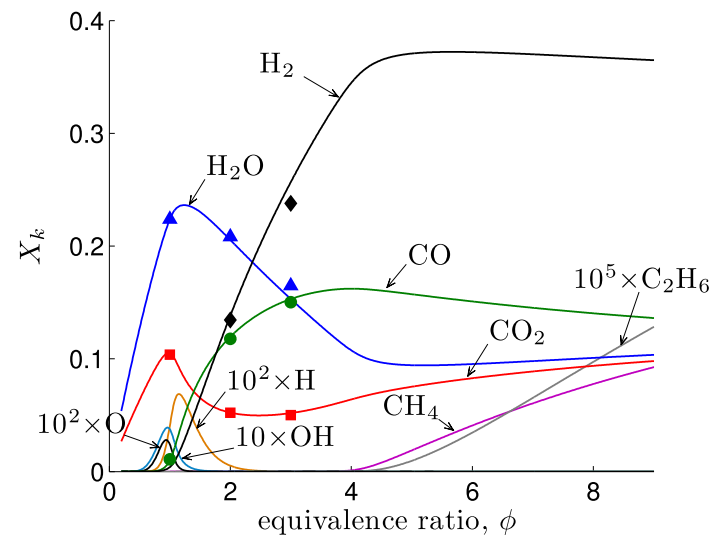

Fig. 5 - Molar fractions (above the value $10^{-6}$ ) of species at chemical equilibrium composition. Symbols indicate the value obtained for freely-propagating premixed-flame computations. Calculated for standard conditions $(p=1$ atm and $\left.T_{u}=300 \mathrm{~K}\right)$. order windward differences and diffusive terms with secondorder central differences. Grid independence was checked by doubling the number of points and checking that the maximum variation of temperature and species mass fraction at the exit was smaller than $0.1 \%$. The code LFLAM searches for steady-state solutions using a Newton method. If the iteration does not converge, the code changes to a transient method in order to reach a new solution.

\section{Results}

Spatially resolved profiles of gas temperature and mole fractions of major chemical species are presented in this

\section{Table 1 - Summary of cases.}

\begin{tabular}{|c|c|c|c|c|}
\hline \multirow[t]{2}{*}{$L(\mathrm{~cm})$} & $b\left(\mathrm{~W} / \mathrm{m}^{3} \mathrm{~K}\right)$ & $\begin{array}{l}\text { fixed } \\
\phi=3\end{array}$ & $\begin{array}{c}\text { fixed } \\
U_{u}=200 \mathrm{~cm} / \mathrm{s} \\
\end{array}$ & $\begin{array}{c}\text { fixed } \\
U_{u}=50 \mathrm{~cm} / \mathrm{s} \\
\end{array}$ \\
\hline & & $U_{u}(\mathrm{~cm} / \mathrm{s})$ & $\phi$ & $\phi$ \\
\hline 2 & $10^{5}$ & $20-77$ & - & $1.5-4.6$ \\
\hline 2 & $10^{6}$ & $35-480$ & $1-7.4$ & - \\
\hline 10 & $10^{5}$ & $25-340$ & 3 & $1.5-9$ \\
\hline 10 & $10^{6}$ & $40-2000$ & $1-9$ & - \\
\hline
\end{tabular}



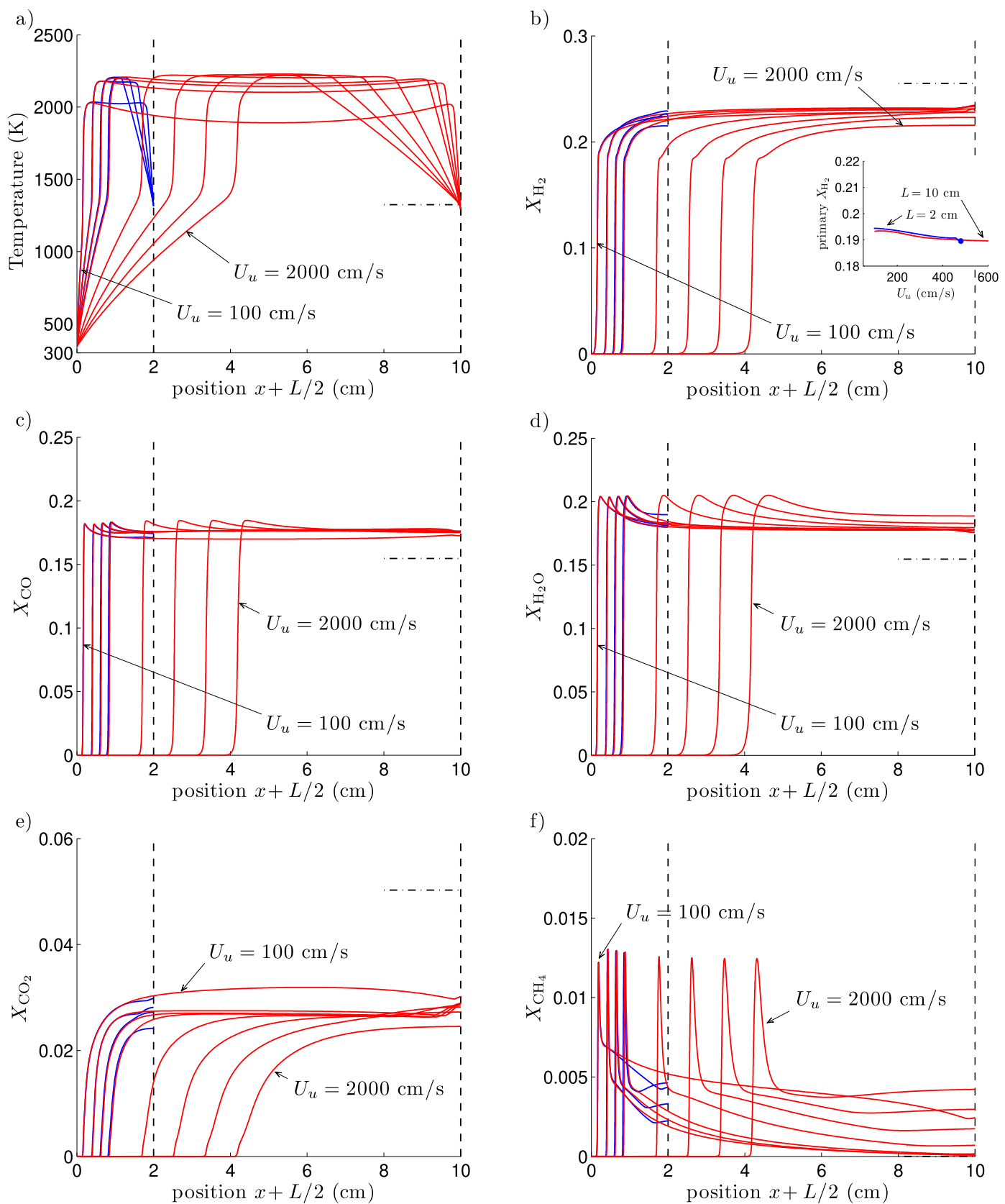

Fig. 6 - Profiles of gas temperature, hydrogen, carbon monoxide, water, carbon dioxide, and methane molar fractions along the channel. Calculated for $L=2 \mathrm{~cm}$ (blue curves in the web version of this article) with inflow velocities $U_{u}=\{100,200,300,400\} \mathrm{cm} / \mathrm{s}$ and for $L=10 \mathrm{~cm}$ (red curves) with $U_{u}=\{100,200,300,400,800,1200,1600,2000\} \mathrm{cm} / \mathrm{s}$, for the case with $\phi=3, T_{u}=343 \mathrm{~K}$ and $b=10^{6} \mathrm{~W} /\left(\mathrm{m}^{3} \mathrm{~K}\right)$. Dot-dashed lines correspond to chemical equilibrium values. The inset in b) shows the molar fraction of $\mathrm{H}_{2}$ in the primary formation with the inflow velocity. (For interpretation of the references to colour in this figure legend, the reader is referred to the Web version of this article.)

section for $T_{u}=343 \mathrm{~K}$ and atmospheric pressure. We divide the study in two main parts: first, in Section Solutions at a fixed equivalence ratio we vary the inflow velocity at a fixed equivalence ratio $\phi=3$ and, second, in Section Solutions at a fixed gas inflow velocity we vary the equivalence ratio at a fixed inflow velocity $U_{u}=200 \mathrm{~cm} / \mathrm{s}$. In $\mathrm{Sec}-$ tions Efficiency of the reforming process and Hydrocarbon emissions analysis of the efficiency and soot precursors, respectively, are given, including studies with fixed inflow velocity $U_{u}=50 \mathrm{~cm} / \mathrm{s}$. A summary of the cases under analysis is given in Table 1.

In all cases, flames are stabilized in the channel as observed experimentally [12-14]. Solutions corresponding to flames crossing the middle point of the channel, which according to Ref. [35] are unstable, are not captured by the present formulation. 

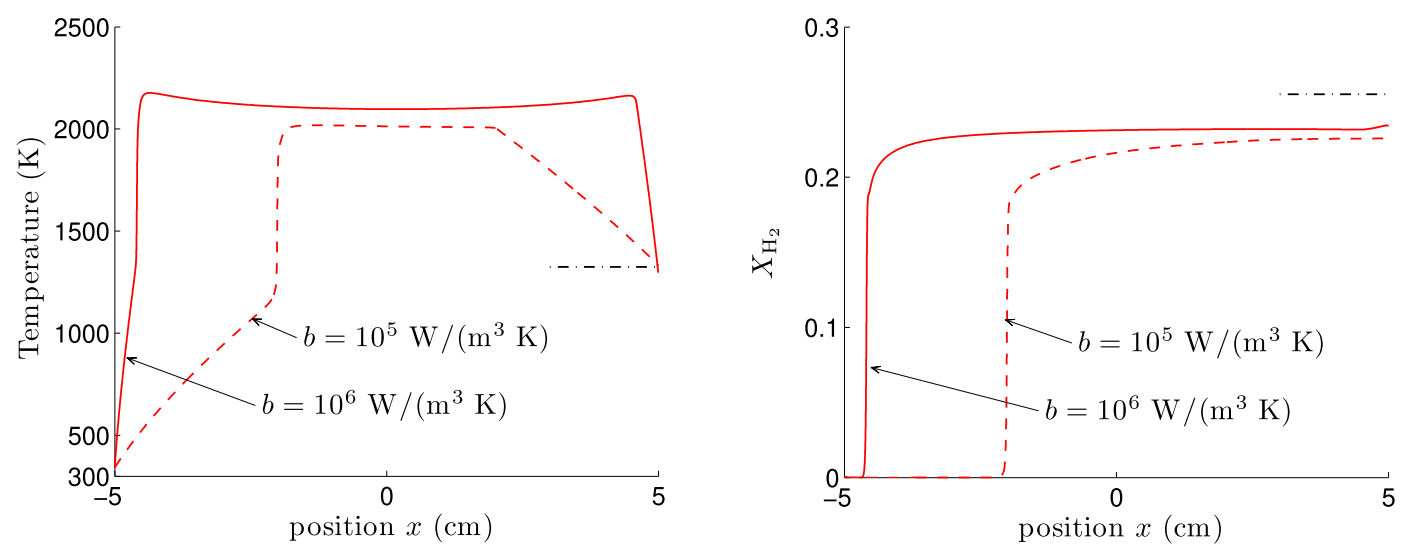

Fig. 7 - Profiles of gas temperature and hydrogen molar fraction along the channel for $L=10 \mathrm{~cm}$. Calculated for $\phi=3, U_{u}=$ $200 \mathrm{~cm} / \mathrm{s}, T_{u}=343 \mathrm{~K}$, and $b=10^{6} \mathrm{~W} /\left(\mathrm{m}^{3} \mathrm{~K}\right.$ ) (solid curve) and $b=10^{5} \mathrm{~W} /\left(\mathrm{m}^{3} \mathrm{~K}\right)$ (dashed curve). Dot-dashed lines correspond with values given by chemical equilibrium.

\section{Solutions at a fixed equivalence ratio}

The structure of methanol partial oxidation is investigated first in Fig. 6 at a fixed equivalence ratio $\phi=3$ and conductivity factor $b=10^{6} \mathrm{~W} /\left(\mathrm{m}^{3} \mathrm{~K}\right)$ for two channel lengths $L=2$ and $10 \mathrm{~cm}$. Three different stages are observed: 1) An inert preheat zone, where heat transfer with the adjacent channels increases the temperature of the fresh gas until ignition occurs. For a given equivalence ratio, the residence time of the fresh gases in the preheat zone, or induction time, depends mainly on the amount of heat recirculating and thus decreases with the increase of the heat conductivity factor. For example, for $\phi=3$, the induction time is $1 \mathrm{~ms}$ for $b=10^{6} \mathrm{~W} /\left(\mathrm{m}^{3} \mathrm{~K}\right)$ and $7 \mathrm{~ms}$ for $b=10^{5} \mathrm{~W} /\left(\mathrm{m}^{3} \mathrm{~K}\right)$. The length of the preheat zone increases linearly with the inflow velocity. 2) A reaction zone, where methanol is partially oxidized at high temperature and $\mathrm{H}_{2} \mathrm{O}$ and $\mathrm{CO}$ molecules, as well as a significant amount of $\mathrm{H}_{2}$, are produced. Because of its relative importance in the total amount of produced hydrogen, we shall call primary the

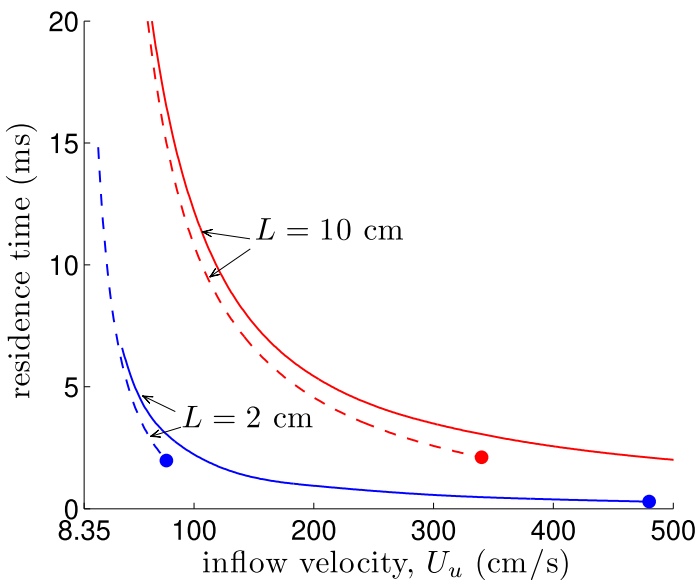

Fig. 8 - Variation of the residence time in the postcombustion zone with the inflow velocity for two different lengths of the reactor. Calculated for $b=10^{6} \mathrm{~W} /\left(\mathrm{m}^{3} \mathrm{~K}\right.$ ) (solid lines) and $b=10^{5} \mathrm{~W} /\left(\mathrm{m}^{3} \mathrm{~K}\right)$ (dashed lines) with $\phi=3$ and $\mathrm{T}_{u}=343 \mathrm{~K}$. The solid circles indicate the blow-off limit. hydrogen production in this zone [19]. This reaction zone has typically $1 \mathrm{~mm}$ length. 3) A post-combustion zone, where $\mathrm{H}_{2} \mathrm{O}$ reacts with $\mathrm{CH}_{4}$ and $\mathrm{CO}$ (and unburned methanol if it exists) resulting in secondary hydrogen formation. This large postcombustion zone comprises slow reactions (reforming and water-gas-shift).

Because it occurs in the high temperature, fast chemistry region, primary $\mathrm{H}_{2}$ formation does not depend on the inflow velocity value. This can be verified in Fig. $6 \mathrm{~b}$ ), where two regions can be distinguished for each $\mathrm{X}_{\mathrm{H}_{2}}$ profile: a region of rapid formation of $\mathrm{H}_{2}$ (the reaction zone) and a region of slow formation of $\mathrm{H}_{2}$ (the post-flame zone). The value of $\mathrm{X}_{\mathrm{H}_{2}}$ measured at the end of the reaction zone as a function of the inflow velocity is plotted in the inset of Fig. 6b). As can be seen, primary formation $\left(\mathrm{X}_{\mathrm{H}_{2}} \approx 0.19\right)$ is nearly independent of the value of the velocity. Primary formation of $\mathrm{H}_{2}$ corresponds to approximately $70 \%$ of the total hydrogen conversion relative

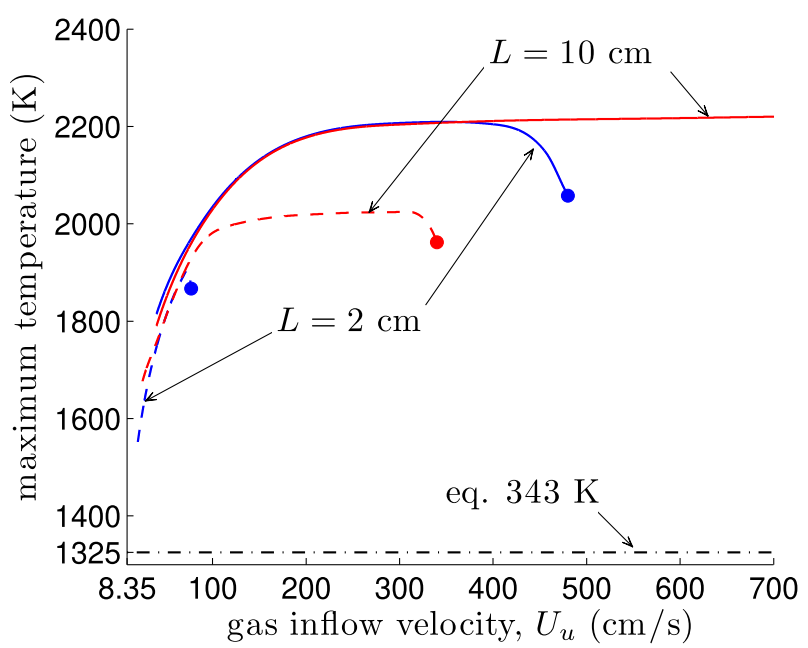

Fig. 9 - Maximum gas temperature inside the channel as a function of the inflow velocity for $L=2 \mathrm{~cm}$ and $L=10 \mathrm{~cm}$. Calculated for $b=10^{6} \mathrm{~W} /\left(\mathrm{m}^{3} \mathrm{~K}\right)$ (solid curves) and $b=10^{5}$ $\mathrm{W} /\left(\mathrm{m}^{3} \mathrm{~K}\right)$ (dashed curves) with $\phi=3$ and $\mathrm{T}_{u}=343 \mathrm{~K}$. Dotdashed line corresponds with the adiabatic temperature. The solid circles indicate the blow-off limit. 


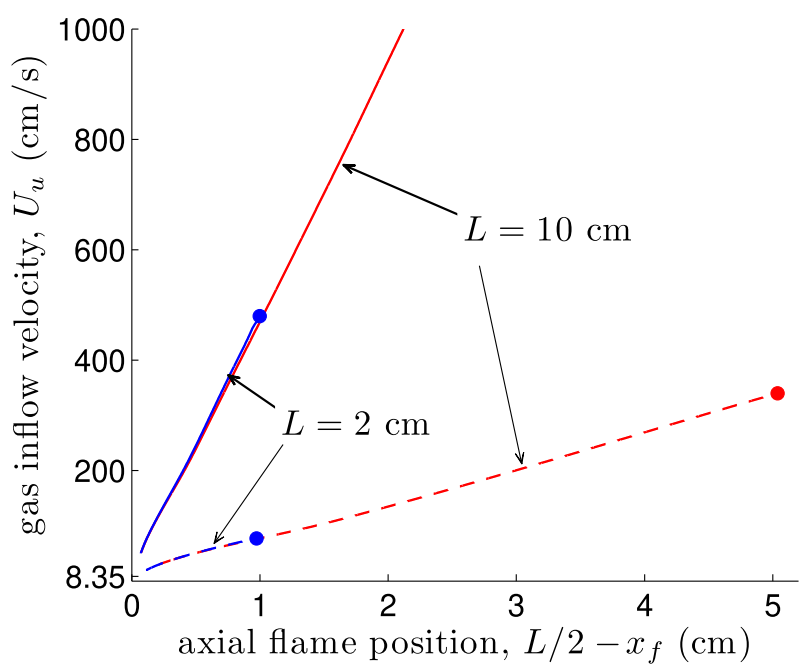

Fig. 10 - Gas inflow velocity versus the position of the flame in the channel. Calculated for $b=10^{6} \mathrm{~W} /\left(\mathrm{m}^{3} \mathrm{~K}\right)$ (solid lines) and $b=10^{5} \mathrm{~W} /\left(\mathrm{m}^{3} \mathrm{~K}\right)$ (dashed lines) with $\phi=3$ and $T_{u}=343 \mathrm{~K}$. The solid circles indicate the blow-off limit.

to thermodynamic equilibrium (marked in Fig. 6b) with dotdashed line). The value of $\mathrm{X}_{\mathrm{H}_{2}}$ in the exhaust gas, however, does depend on the inflow velocity: large inflow rates situate the flame close to the channel middle, resulting in too short post-combustion zones, while very slow inflow rates result in low combustion temperature and therefore a slow rate for the reforming reactions. Note that the concentrations of $\mathrm{CO}, \mathrm{H}_{2} \mathrm{O}$ and $\mathrm{CH}_{4}$ decrease in the post-combustion zone.

Fig. 7 presents the profiles of gas temperature and hydrogen molar fraction for two different values of $b$, the conductivity factor. As can be seen, a decrease of the wall thermal conductivity reduces the temperature of the gas and shifts the reaction zone position inside the channel, but the amount of $\mathrm{H}_{2}$ produced in the reaction zone $\left(\mathrm{X}_{\mathrm{H}_{2}} \approx 0.19\right)$ is not affected. However, the amount of $\mathrm{H}_{2}$ produced in the secondary formation zone does change significatively with the wall conductivity: for the less conducting wall the length of this secondary zone and consequently the residence time and the secondary $\mathrm{H}_{2}$ production are reduced.

In Fig. 8 we show the characteristic residence time of the gas products in the post-combustion zone as a function of the inflow velocity for different conductivity factors and lengths of the reactor. The residence time is calculated by integrating the inverse of the gas velocity $U$ along the channel from the position of the reaction zone at $x=-x_{f}$ to the outlet at $x=L / 2$. The position of the reaction zone is calculated as the position of the maximum heat release rate given by the expression $\sum_{k=1}^{N} h_{k} \dot{\omega}_{k}$. As can be seen in Fig. 8, the residence time in the post-combustion zone is of the order of miliseconds. This is significantly smaller than the $20 \mathrm{~s}$ associated to freelypropagating flames at $\phi=3$. The residence time increases for longer reactors with more conductive walls, so one can expect higher amounts of secondary $\mathrm{H}_{2}$ production. The solid circles in Fig. 8 correspond to reaction zones crossing to the unstable region $x>0$, which, in practice, indicates the blow-off limit.

Fig. 9 displays the maximum gas temperature in the channel as a function of the inflow velocity. It shows that the maximum temperature reaches a certain value and then saturates as the inflow velocity increases (except in a region close to the blow-off limit). This saturation is not captured by analytical models [28], probably due to the absence of finite chemistry effects in those models. For low inflow velocities the reaction zone is located close to the inlet, and as a consequence the amount of fresh gases preheating and the maximum flame temperature decrease. When the inflow velocity tends to the limiting value of $8.35 \mathrm{~cm} / \mathrm{s}$ (corresponding to the velocity of the freely propagating adiabatic flame at $\phi=3$ ) the flame can no longer be stabilized inside the channel. In this case, heat recirculation has no effect and the flame propagates upstream (flashback) with the maximum gas temperature corresponding to the adiabatic value of $1325 \mathrm{~K}$. Fig. 9 also shows that the maximum temperature depends on the conductivity factor but not on the length of the reactor. The operating point that maximizes the secondary formation
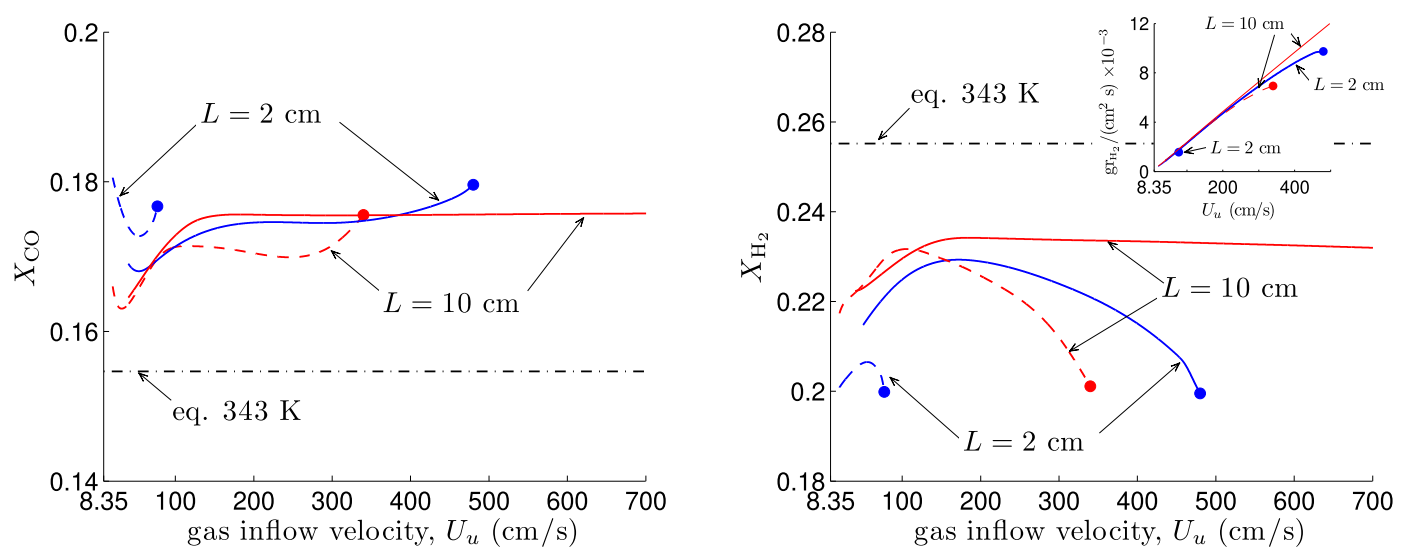

Fig. 11 - Mole fractions of carbon monoxide (left) and hydrogen molar fraction (right) at the exit of the channel as a function of the inflow velocity. Calculated for $b=10^{6} \mathrm{~W} /\left(\mathrm{m}^{3} \mathrm{~K}\right)$ (solid curves) and $b=10^{5} \mathrm{~W} /\left(\mathrm{m}^{3} \mathrm{~K}\right)$ (dashed curves) with $\phi=3$ and $T_{u}=$ $343 \mathrm{~K}$. Dot-dashed lines correspond to equilibrium conditions. The solid circles indicate the blow-off limit. The inset shows the hydrogen conversion rate. 
a)

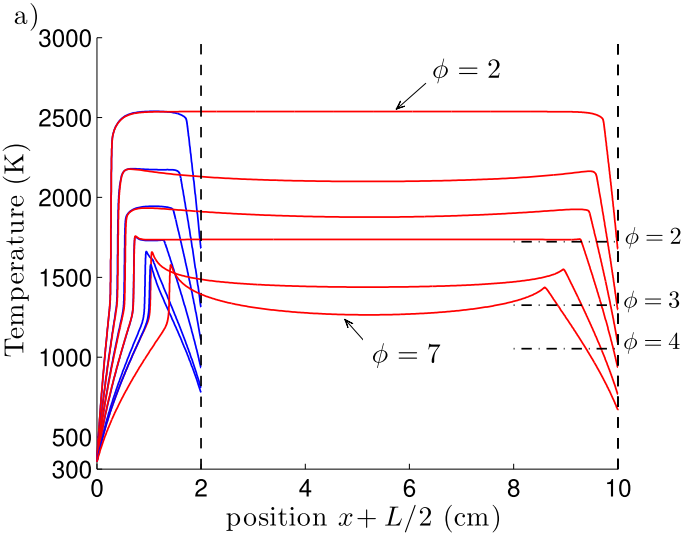

c)

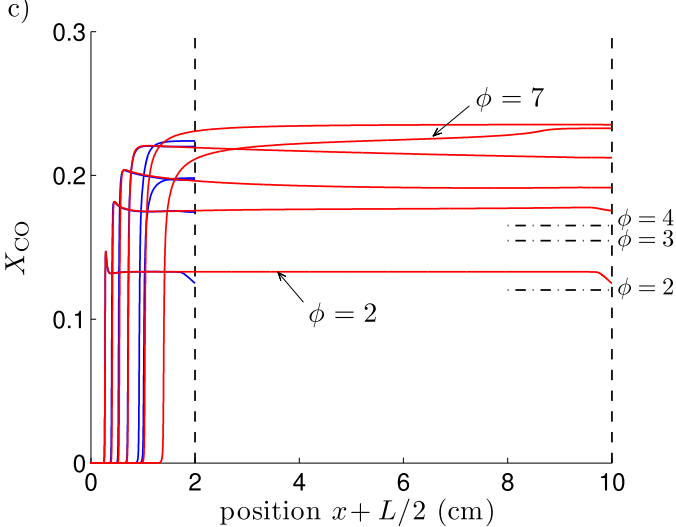

e)

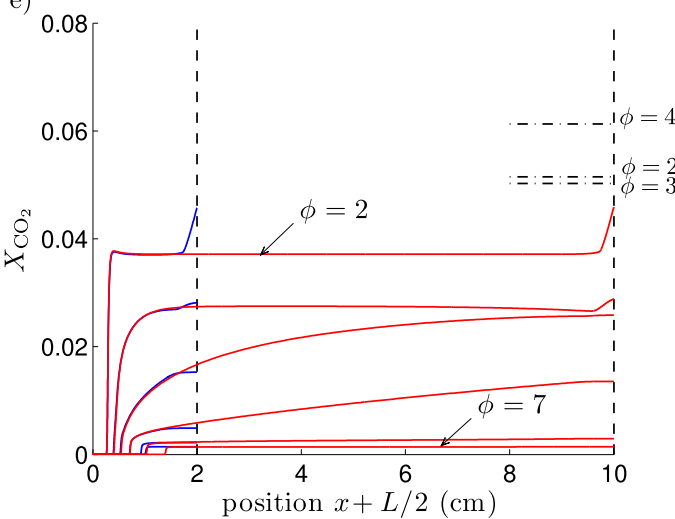

b)

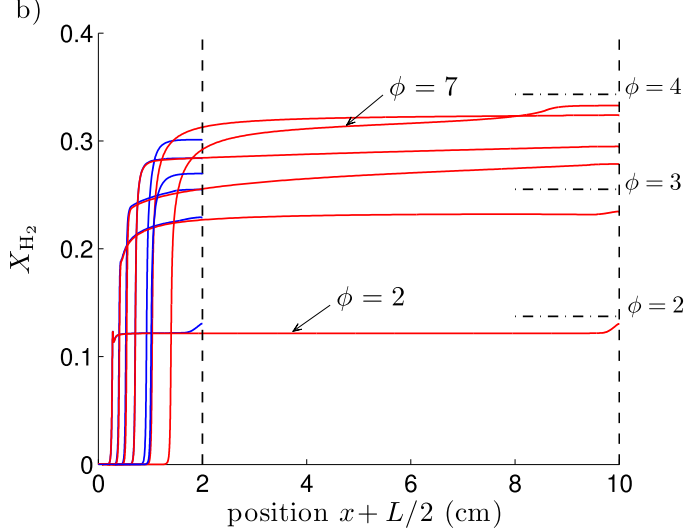

d)
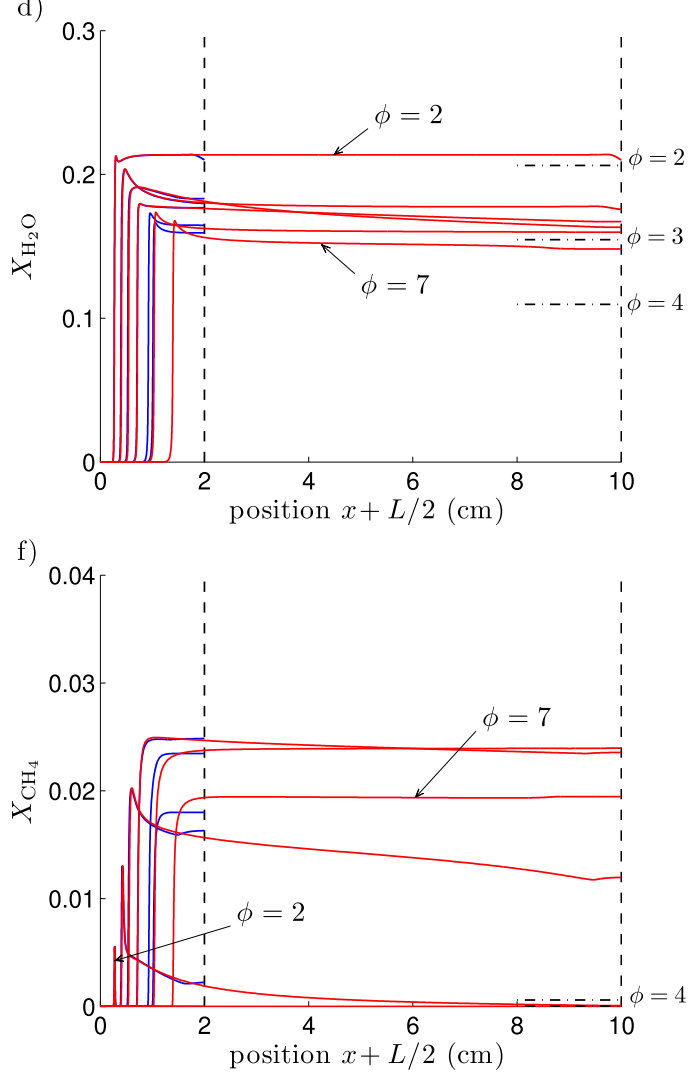

Fig. 12 - Profiles of gas temperature, hydrogen, carbon monoxide, water, carbon dioxide, and methane molar fractions along the channel for $L=2 \mathrm{~cm}$ and $\mathrm{L}=10 \mathrm{~cm}$ (blue and red curves, respectively, in the web version of this article). Calculated for equivalence ratios $\phi=\{2,3,4,5,6,7\}$ with $U_{u}=200 \mathrm{~cm} / \mathrm{s}, T_{u}=343 \mathrm{~K}$ and $b=10^{6} \mathrm{~W} /\left(\mathrm{m}^{3} \mathrm{~K}\right)$. Dot-dashed lines correspond to chemical equilibrium values given at $\phi=\{2,3,4\}$. (For interpretation of the references to colour in this figure legend, the reader is referred to the Web version of this article.)

of $\mathrm{H}_{2}$ is given by an inflow velocity that maximizes the reaction temperature with the longest residence time. Following this criterion, maximum hydrogen production will occur for the case with $L=10 \mathrm{~cm}$ and $b=10^{6} \mathrm{~W} /\left(\mathrm{m}^{3} \mathrm{~K}\right)$ at $U_{u} \approx 200 \mathrm{~cm} / \mathrm{s}$.

The position of the reaction zone as a function of the gas inflow velocity is shown in Fig. 10. In this figure we clearly see the linear dependence of the length of the preheat zone with the inflow velocity. The slope of these curves is the inverse of a time related to the induction time. For a given inflow velocity, the length of the reactor does not change the location of the reaction zone. The range of flow rates that result in steady operation of the reactor increases with $\mathrm{L}$.

Fig. 11 shows the molar fraction of $\mathrm{CO}$ and $\mathrm{H}_{2}$ measured at the exit of the channel as a function of the inflow velocity. The effect of the inflow velocity on the amount of $\mathrm{CO}$ and $\mathrm{H}_{2}$ produced is weak. $\mathrm{CO}$ in the exhaust gas (compared to the value produced in the reaction zone, e.g., $\mathrm{X}_{\mathrm{CO}} \approx 0.18$ ) decreases for low gas inflow velocities, because the residence time of the gas products in the post-combustion zone is longer. The concentration of $\mathrm{H}_{2}$ is maximum for the reactor with $\mathrm{L}=10$ 
$\mathrm{cm}$ and $b=10^{6} \mathrm{~W} /\left(\mathrm{m}^{3} \mathrm{~K}\right)$ at the operating point of $U_{u} \approx 200 \mathrm{~cm} /$ $\mathrm{s}$, in agreement with the criterion proposed above. The available power in terms of the hydrogen conversion rate (grams of $\mathrm{H}_{2}$ per unit cross area per unit time) is shown in the inset of Fig. 11. A reactor channel with just a cross section of $1 \mathrm{~mm}^{2}$ will be able to produce enough hydrogen flow $\left(10^{-5} \mathrm{gr}_{\mathrm{H}_{2}} / \mathrm{s}\right)$ at $U_{u}=50 \mathrm{~cm} / \mathrm{s}$ to feed a $1 \mathrm{~W} / 1 \mathrm{~A}$ micro fuel cell [47]. The available power in watts can be obtained multiplying the hydrogen conversion rate by the energy content (heat of combustion per unit mass of hydrogen $\sim 120 \mathrm{KJ} / \mathrm{gr}_{\mathrm{H}_{2}}$ ). The operating range of the reactor increases with the length of the channel and the conductivity factor.

\section{Solutions at a fixed gas inflow velocity}

Fig. 12 displays gas temperature and mole fraction profiles for a fixed inlet velocity $U_{u}=200 \mathrm{~cm} / \mathrm{s}$ as the equivalence ratio is varied. In the figure we plot curves for $L=2 \mathrm{~cm}$ and $\mathrm{L}=10 \mathrm{~cm}$ with $b=10^{6} \mathrm{~W} /\left(\mathrm{m}^{3} \mathrm{~K}\right)$. As can be seen, mixtures very far from the rich flammability limit can be burnt. The $\mathrm{H}_{2}$ mole fraction at the outlet increases with the equivalence ratio, mainly due to the increase of the primary formation. Secondary formation of $\mathrm{H}_{2}$ occurs downstream, depending on the value of the equivalence ratio. For example, for $\phi=2$ the secondary $\mathrm{H}_{2}$ formation is negligible because of the absence of methanol in the post-combustion zone (absence of the reforming reactions). For $\phi>2$ there exist secondary $\mathrm{H}_{2}$ formation. Methanol is consumed in the post-combustion zone of the channel together with a reduction of the $\mathrm{CO}$ and $\mathrm{H}_{2} \mathrm{O}$ concentrations. The longer reactors produce more hydrogen due to the increase of the residence time. As the rate of the reforming reactions depends on the combustion temperature, which in turn depends on the equivalence ratio, the secondary $\mathrm{H}_{2}$ formation is also affected by the equivalence ratio. Note that for $\phi>4, \mathrm{CH}_{4}$ molecules are not fully consumed inside the reactor.

In Fig. 13 we plot the molar fractions of $\mathrm{CO}$ and $\mathrm{H}_{2}$ measured at the exit of the channel as a function of the equivalence ratio. Above $\phi>3$ noticeable differences emerge between the composition of the exhaust gas and the equilibium state. Peak $\mathrm{CO}$ and $\mathrm{H}_{2}$ mole fractions are found at $\phi \approx 6$ with peak hydrogen conversion rate of $8 \cdot 10^{-3} \mathrm{gr} \mathrm{H}_{2} /\left(\mathrm{cm}^{2} \mathrm{~s}\right)$.
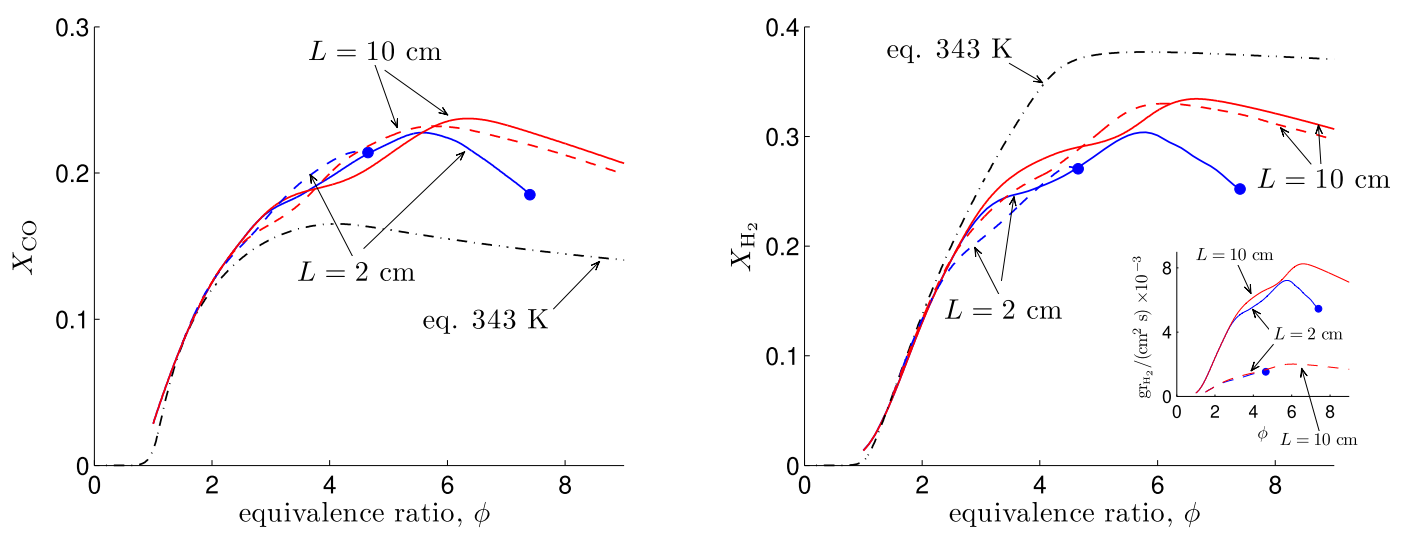

Fig. 13 - Mole fractions of carbon monoxide (left) and hydrogen molar fraction (right) at the exit of the channel as a function of the equivalence ratio. Calculated for $U_{u}=200 \mathrm{~cm} / \mathrm{s}$ and $b=10^{6} \mathrm{~W} /\left(\mathrm{m}^{3} \mathrm{~K}\right)$ (solid curves) and for $U_{u}=50 \mathrm{~cm} / \mathrm{s}$ and $b=10^{5} \mathrm{~W} /$ $\left(\mathrm{m}^{3} \mathrm{~K}\right)$ (dashed curves) with $\mathrm{T}_{u}=343 \mathrm{~K}$. Dot-dashed curves correspond to equilibrium conditions. The solid circles indicate the blow-off limit. The inset shows the hydrogen conversion rate.
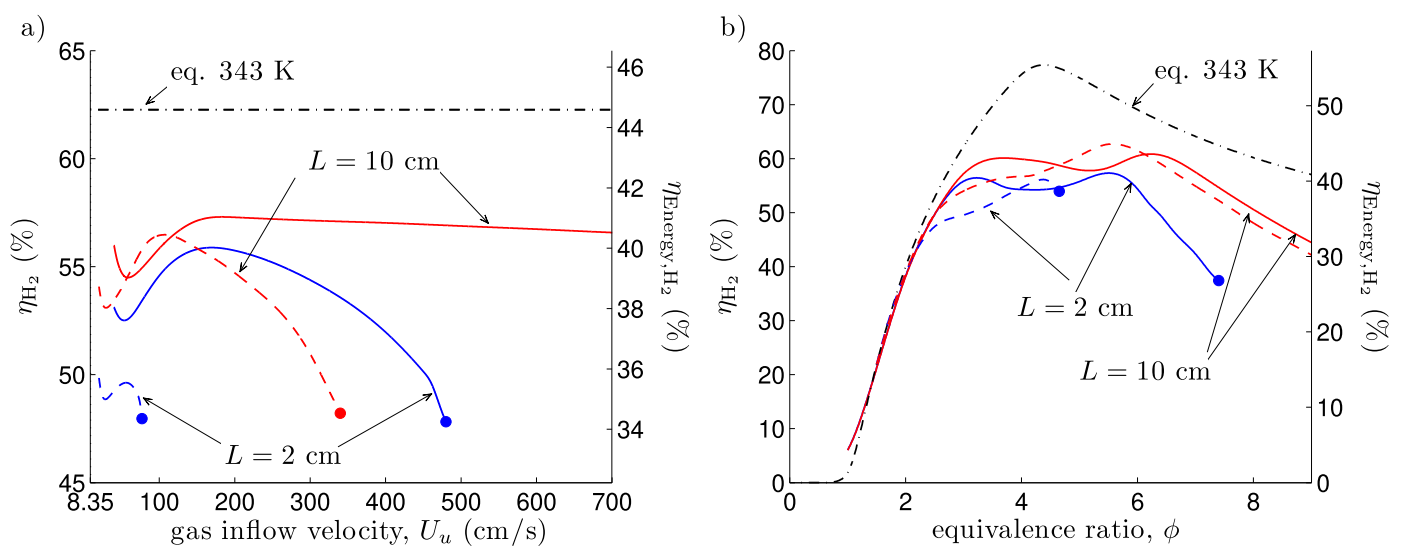

Fig. 14 - Measurement of the conversion efficiencies variation at the exit of the channel. a) for fixed $\varphi=3$; b) for fixed $U_{u}=$ $200 \mathrm{~cm} / \mathrm{s}$ (solid curve) and $U_{u}=50 \mathrm{~cm} / \mathrm{s}$ (dashed curve). Calculated for $b=10^{6} \mathrm{~W} /\left(\mathrm{m}^{3} \mathrm{~K}\right)\left(\right.$ solid curves) and $b=10^{5} \mathrm{~W} /\left(\mathrm{m}^{3} \mathrm{~K}\right)$ (dashed curves) with $T_{u}=343 \mathrm{~K}$. Dot-dashed curves correspond to equilibrium conditions. The solid circles indicate the blow-off limit. 

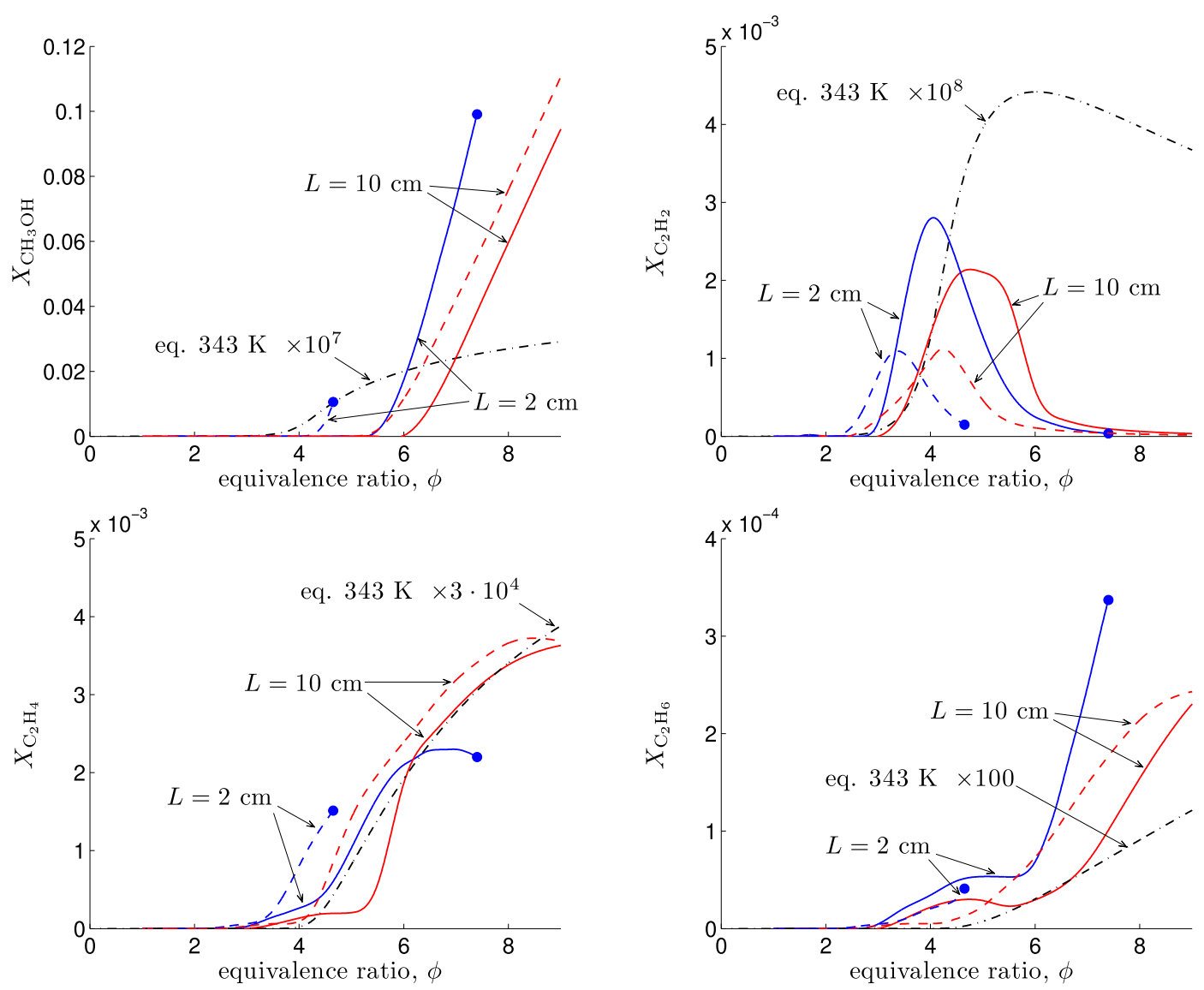

Fig. 15 - Mole fractions of methanol $\left(\mathrm{CH}_{3} \mathrm{OH}\right)$, acetylene $\left(\mathrm{C}_{2} \mathrm{H}_{2}\right)$, ethylene $\left(\mathrm{C}_{2} \mathrm{H}_{4}\right)$ and ethane $\left(\mathrm{C}_{2} \mathrm{H}_{6}\right)$ molar fractions as a function of the equivalence ratio at the exit of the channel. Calculated for $U_{u}=200 \mathrm{~cm} / \mathrm{s}$ with $\mathrm{b}=10^{6} \mathrm{~W} /\left(\mathrm{m}^{3} \mathrm{~K}\right)(\mathrm{solid} \mathrm{curves})$ and for $U_{u}=50 \mathrm{~cm} / \mathrm{s}$ with $b=10^{5} \mathrm{~W} /\left(\mathrm{m}^{3} \mathrm{~K}\right.$ ) (dashed curves). Dot-dashed curves correspond with equilibrium conditions. The solid circle indicates the blow-off limit.

\section{Efficiency of the reforming process}

Following $[13,14]$, we use two metrics to evaluate the efficiency of the microreactor: the hydrogen conversion efficiency $\eta_{\mathrm{H}_{2}}$ and the hydrogen energy conversion efficiency $\eta_{\text {Energy, } \mathrm{H}_{2}}$.

The hydrogen conversion efficiency (also called $\mathrm{H}_{2}$ yield) is defined as the ratio of $\mathrm{H}_{2}$ moles produced per unit time at the exit of the reactor over the $\mathrm{H}_{2}$ moles that would be produced if all the atomic hydrogen in the fuel was converted to $\mathrm{H}_{2}$. The $\mathrm{H}_{2}$ yield is given by the expression

$\eta_{\mathrm{H}_{2}}=\dot{\mathrm{N}}_{\mathrm{H}_{2}, \text { out }} / 2 \dot{\mathrm{N}}_{\mathrm{CH}_{3} \mathrm{OH}, u}$,

where $\dot{N}_{k}$ is the molar flow rate of the species $k$ and the subindices "out" and " $u$ " stand for the condition at the exit and at the unburned mixture, respectively. The molar flow rate can be calculated as $\dot{N}_{k}=X_{k} \dot{N}_{T}$, with $X_{k}$ the molar fraction of the species $\mathrm{k}$ and $\dot{N}_{T}=\sum \dot{N}_{k}$ the total molar flow rate. The total molar flow rate at the outlet of the reactor was calculated from the nitrogen balance $X_{N_{2}, \text { out }} \dot{N}_{T, \text { out }}=X_{\mathrm{N}_{2}, u} \dot{N}_{T, u}$.

Since the overall energy conversion involves the production of hydrogen from methanol to be later converted into a different form of energy, another important parameter is the energy efficiency of the reforming process. The hydrogen energy conversion efficiency is defined as the ratio of the energy bound in $\mathrm{H}_{2}$ produced in the reformer over the input energy in the reactant fuel and it is computed here as

$\eta_{\text {Energy, } \mathrm{H}_{2}}=\frac{\dot{\mathrm{N}}_{\mathrm{H}_{2}, \text { out }}\left(-\Delta h_{\mathrm{H}_{2}}\right)}{\dot{\mathrm{N}}_{\mathrm{CH}_{3} \mathrm{OH}, \mathrm{u}}\left(-\Delta h_{\mathrm{CH}_{3} \mathrm{OH}}\right)}$,

where $-\Delta h_{\mathrm{H}_{2}}$ and $-\Delta h_{\mathrm{CH}_{3} \mathrm{OH}}$ stand for the heats of combustion (per unit mole) of hydrogen and methanol, respectively. Therefore $\eta_{\text {Energy, } \mathrm{H}_{2}}=2 \eta_{\mathrm{H}_{2}} \Delta h_{\mathrm{H}_{2}} / \Delta h_{\mathrm{CH}_{3} \mathrm{OH}}$. According to Figs. 13 and 15, $\mathrm{CO}$ and $\mathrm{CH}_{3} \mathrm{OH}$ concentrations are important at large equivalence ratios. An alternative energy efficiency including the $\mathrm{CO}$ and $\mathrm{CH}_{3} \mathrm{OH}$ energy content is

$\eta_{\text {Energy }}=\frac{\dot{\mathrm{N}}_{\mathrm{H}_{2}, \text { out }}\left(-\Delta h_{\mathrm{H}_{2}}\right)+\dot{\mathrm{N}}_{\mathrm{CO}, \text { out }}\left(-\Delta h_{\mathrm{CO}}\right)+\dot{\mathrm{N}}_{\mathrm{CH}_{3} \mathrm{OH}, \text { out }}\left(-\Delta h_{\mathrm{CH}_{3} \mathrm{OH}}\right)}{\dot{N}_{\mathrm{CH}_{3} \mathrm{OH}, u}\left(-\Delta h_{\mathrm{CH}_{3} \mathrm{OH}}\right)}$.

Fig. 14 shows the conversion efficiencies as a function of the inflow velocity (left) and the equivalence ratio (right) for reactors with $L=2 \mathrm{~cm}$ and $L=10 \mathrm{~cm}$ and $b=10^{5} \mathrm{~W} /\left(\mathrm{m}^{3} \mathrm{~K}\right)$ and $b=10^{6} \mathrm{~W} /\left(\mathrm{m}^{3} \mathrm{~K}\right)$. The maximum efficiency at $\phi=3$ is found for the channel with $L=10 \mathrm{~cm}$ and $b=10^{6} \mathrm{~W} /\left(\mathrm{m}^{3} \mathrm{~K}\right)$ at a velocity $U_{u} \approx 200 \mathrm{~cm} / \mathrm{s}$, again in agreement with the criterion proposed above (i.e., the reaction zone is located in a position that maximizes the secondary formation of $\mathrm{H}_{2}$ ). Fig. 14 (left) 
indicates that longer and more conductive reactors are more efficient. This effect is not clearly seen in Fig. 14 (right) because in this figure we plot computations corresponding to reactors with different wall conductivities and different inflow velocities. Even if maximum $\mathrm{H}_{2}$ concentrations are predicted at $\phi \approx$ 6 according to Fig. 13, this does not necessarily mean that this operating point is the most efficient. The process reaches very similar conversion efficiencies for a wide range of equivalence ratios between $\phi=3$ and 6 . The energy efficiency $\eta_{\text {Energy }}$ can double that of $\eta_{\text {Energy. } \mathrm{H}_{2}}$.

\section{Hydrocarbon emissions}

Soot and hydrocarbon emissions have been reported experimentally for the reactor prototype [12-14]. Gas-phase hydrocarbons as $\mathrm{C}_{2} \mathrm{H}_{2}, \mathrm{C}_{2} \mathrm{H}_{4}$ and $\mathrm{C}_{2} \mathrm{H}_{6}$ are known to be precursors for soot formation via linking of polycyclic aromatic hydrocarbon species [48]. We show in Fig. 15 the molar fractions of unburned methanol and soot precursors in the exhaust gas as a function of the reactant mixture equivalence ratio. These species concentrations are several orders of magnitude higher than those obtained at equilibrium and increase substantially above $\phi>3$. These concentrations are reduced for the longer reactors because of the increase in the residence time. As the wall conductivity is increased the precursor concentrations are reduced because of the higher reaction temperature. Our analysis suggests that for a given reactor, the richer values of the equivalence ratio should be avoided, because of the possible deposit of soot on the channel walls. A safer and still effective operating point in terms of $\mathrm{H}_{2}$ yield should be chosen around $\phi \approx 3$.

\section{Conclusions}

In this paper we present a numerical simulation of very rich methanol-air combustion in a counter-current microchannel reactor with heat recirculation using detailed gas-phase chemical kinetics and transport. Within the framework of the narrow-channel approximation, this problem can be reduced to a one-dimensional model for a single channel. The model burner performance is investigated in terms of the equivalence ratio, the gas inflow velocity, the length of the reactor, and the conductivity of the wall material. The simulations reveal that the partial oxidation process in the channel can be described by three different stages: (1) an inert preheat zone, where the temperature of fresh reactants is increased by heat exchange with the product stream in the adjacent channels, (2) an exothermic reaction zone, where partial oxidation produces most of the $\mathrm{H}_{2}$ (primary formation), and (3) a post-combustion zone, where endothermic reforming reactions contribute to secondary formation of $\mathrm{H}_{2}$. The primary formation of $\mathrm{H}_{2}$ only depends on the reactant mixture equivalence ratio, whereas the secondary formation depends mainly on the inflow velocity and the wall conductivity factor $b=2 \lambda_{\mathrm{w}} /\left(d d_{\mathrm{w}}\right)$. As an example, for a methanol-air mixture with $\phi=3$, primary formation accounts for approximately $70 \%$ of the total hydrogen conversion relative to thermodynamic equilibrium.

The simulations show hydrogen and hydrogen-energy conversion efficiencies of the order of $60 \%$ and $40 \%$, respectively, in a range of equivalence ratios between $\phi=3$ and 6 with small influence of the gas inflow velocity. The available power output (in terms of hydrogen conversion rate) is easily scalable by increasing the number of channels. For a single channel reactor with a cross section of $1 \mathrm{~mm}^{2}$ and length $L=2$ $\mathrm{cm}$ the idealized power output can reach up to 10W. Experimental validation of the findings of this work, in a manner similar to that developed by Ellzey et al. [12-14], is desirable in the future.

\section{Acknowledgments}

This research was supported by projects \#ENE2015-65852-C21-R and \#ENE2015-65852-C2-2-R (MINECO/FEDER, UE).

\section{R E F E R E N C E S}

[1] Fernández-Pello AC. Micropower generation using combustion: issues and approaches. Proc Combust Inst 2002;29:883-99.

[2] Kaisare NS, Vlachos DG. A review on microcombustion: fundamentals, devices and applications. Prog Energy Combust Sci 2012;38:321-59.

[3] Dunn-Rankin D, Leal EM, Walther DC. Personal power systems. Prog Energy Combust Sci 2005;31:422-65.

[4] Holladay JD, Jones EO, Phelps M, Hu J. High-efficiency microscale power using a fuel processor and fuel cell. In: Paper 4559-20, SPIE micromachining and microfabrication, San Francisco, CA, October 21-24, 2001; 2001.

[5] Albrecht BA, Kok JBW, Dijkstra N, van der Meer T. Prediction and measurement of the product gas composition of the ultra rich premixed combustion of natural gas: effects of equivalence ratio, residence time, pressure, and oxygen concentration. Combust Sci Technol 2009;181:433-56.

[6] Pattekar AV, Kothare MV. A microreactor for hydrogen production in micro fuel cell applications. J. Microelectromech. S. 2004;13:7-18.

[7] Won JY, Jun HK, Jeon MK, Woo SI. Performance of microchannel reactor combined with combustor for methanol steam reforming. Catal Today 2006;111:158-63.

[8] Kim T. Micro methanol reformer combined with a catalytic combustor for a PEM fuel cell. Int J Hydrogen Energy 2009;34:6790-8.

[9] Turchetti L, Murmura MA, Monteleone G, Giaconia A, Lemonidou AA, Angeli SD, Palma V, Ruocco C, Annesini MC. Kinetic assessment of Ni-based catalysts in low-temperature methane/biogas steam reforming. Int J Hydrogen Energy 2016;41(38):16865-77.

[10] Murmura MA, Cerbelli S, Annesini MC. Designing the optimal geometry of a membrane reactor for hydrogen production from a pre-reformed gas mixture based on the extent of the reaction boundary layer. Chem. Eng. Process - Process Intensification 2017;120:148-60.

[11] Murmura MA, Cerbelli S, Annesini MC. Modeling fixed bed membrane reactors for hydrogen production through steam reforming reactions: a critical analysis. Membranes 2018;8(2):34.

[12] Schoegl I, Ellzey JL. A mesoscale fuel reformer to produce syngas in portable power systems. Proc Combust Inst 2009;32:3223-30.

[13] Schoegl I, Newcomb SR, Ellzey JL. Ultra-rich combustion in parallel channels to produce hydrogen-rich syngas from propane. Int J Hydrogen Energy 2009;34:5152-63. 
[14] Belmont EL, Solomon SM, Ellzey JL. Syngas production from heptane in a non-catalytic counter-flow reactor. Combust Flame 2012;159:3624-31.

[15] Chen C, Sur S, Thayer J, Pearlman H, Ronney P. A noncatalytic fuel-flexible reformer. In: Paper 070MI-0132, 8th U.S Joint meeting. Combustion Institute; 2013. 2013.

[16] Chen C, Zheng Y, Koli S, Pearlman H, Lawson A, Richard B, Trivedi S, Ronney P. Progress on the development of a SwissRoll fuel reformer for syngas production. In: Paper HT20167277, ASME summer heat transfer conference, Washington, DC, july 2016; 2016.

[17] Lloyd SA, Weinberg FJ. A burner for mixtures of very low heat content. Nature 1974;251:47-9.

[18] Ellzey JL, Belmont EL, Smith CH. Heat recirculating reactors: fundamental research and applications. Prog Energy Combust Sci 2019;72:32-58.

[19] Drayton MK, Saveliev AV, Kennedy LA, Fridman AA, Li Y. Syngas production using superadiabatic combustion of ultrarich methane-air mixtures. Proc Combust Inst 1998;27:1361-7.

[20] Kennedy LA, Bingue JP, Saveliev AV, Fridman AA, Foutko SI. Chemical structures of methane-air filtration combustion waves for fuel-lean and fuel-rich conditions. Proc Combust Inst 2000;28:1431-8.

[21] Pedersen-Mjaares H, Chan L, Mastorakos E. Hydrogen production from rich combustion in a porous media. Int $\mathrm{J}$ Hydrogen Energy 2005;30:579-92.

[22] Dhamrat RS, Ellzey JL. Numerical and experimental study of the conversion of methane to hydrogen in a porous media reactor. Combust Flame 2006;144:698-709.

[23] Toledo M, Bubnovich V, Saveliev A, Kennedy L. Hydrogen production in ultrarich combustion of hydrocarbon fuels in porous media. Int J Hydrogen Energy 2009;34:1818-27.

[24] Toledo M, González F, Ellzey J. Hydrogen production from methanol and ethanol partial oxidation. Energy Fuels 2014:28:3453-9.

[25] Henneke MR, Ellzey JL. Modeling of filtration combustion in a packed bed. Combust Flame 1999;117:832-40.

[26] Schoegl IM, Ellzey JL. Numerical investigation of ultra-rich combustion in counter flow heat exchangers. Combust Sci Technol 2010;182:1413-28.

[27] Belmont EL, Radyjowski P, Ellzey JL. Effect of geometric scale on heat recirculation and syngas production in a noncatalytic counter-flow reformer. Combust Sci Technol 2015;187:874-94.

[28] Schoegl I, Ellzey JL. Superadiabatic combustion in conducting tubes and heat exchangers of finite length. Combust Flame 2007;151:142-59.

[29] Daou J, Matalon M. Influence of conductive heat-losses on the propagation of premixed flames in channels. Combust Flame 2002;128:321-39.

[30] Short M, Kessler DA. Asymptotic and numerical study of variable-density premixed flame propagation in a narrow channel. J Fluid Mech 2009;638:305-37.

[31] Kurdyumov VN, Matalon M. Flame acceleration in long narrow open channels. Proc Combust Inst 2013;34:865-72.
[32] Kurdyumov VN, Matalon M. Self-accelerating flames in long narrow open channels. Proc Combust Inst 2015;35:921-8.

[33] Fursenko RV, Minaev SS, Babkin VS. Thermal interaction of two flame fronts propagating in channels with opposing gas flows. Combust. Explo. Shock. 2001;37:493-500.

[34] Ju Y, Choi CW. An analysis of sub-limit flame dynamics using opposite propagating flames in mesoscale channels. Combust Flame 2003;133:483-93.

[35] Fursenko RV, Minaev SS. Flame stability in a system with counterflow heat exchange. Combust. Explo. Shock. 2005;41:133-9.

[36] Smooke MD, Giovangigli V. Formulation of the premixed and non-premixed test problems. In: Smooke MD, editor. Reduced kinetic mechanisms and asymptotic approximations for methane-air flames, vol. 384 of lecture notes in physics. Springer-Verlag; 1991. p. 1-28.

[37] Williams FA. Combustion theory. 2nd ed. The Benjamin/ Cummings Publisher Company; 1985.

[38] "Chemical-Kinetic mechanisms for combustion Applications", san Diego mechanism web page, mechanical and aerospace engineering (combustion research), University of California at San Diego, Version 16-08-15, http://web.eng.ucsd.edu/mae/groups/combustion/ mechanism.html.

[39] Fernández-Tarrazo E, Sánchez-Sanz M, Sánchez AL, Williams FA. A multipurpose reduced chemical-kinetic mechanism for methanol combustion. Combust Theor Model 2016;20(4):613-31.

[40] Coward HF, Jones GW. Limits of flammability of gases and vapors, Bulletin 503. Washington, D.C.: U.S. Bureau of Mines, U.S. Government Printing Office; 1952.

[41] Seshadri K, Bai XS, Pitsch H. Asymptotic structure of rich methane-air flames. Combust Flame 2002;127:2265-77.

[42] Saeed K, Stone CR. Measurements of the laminar burning velocity for mixtures of methanol and air from a constantvolume vessel using a multizone model. Combust Flame 2004;139:152-66.

[43] Zhang Z, Huang Z, Wang X, Xiang J, Wang X, Miao H. Measurements of laminar burning velocities and markstein lengths for methanol-air-nitrogen mixtures at elevated pressures and temperatures. Combust Flame 2008;155:358-68.

[44] Bischoff KB. A note on boundary conditions for flow reactors. Chem Eng Sci 1961;16:131-3.

[45] http://www.grc.nasa.gov/www/CEAWeb/.

[46] Kee RJ, Grcar JF, Smooke MD, Miller JA. A Fortran program for modeling steady laminar one-dimensional premixed flames. In: Tech. Rep., Sandia National Laboratories report SAND858240; 1985.

[47] Fernández-Moreno J, Guelbenzu G, Martín AJ, Folgado MA, Ferreira-Aparicio P, Chaparro AM. A portable system powered with hydrogen and one single air-breathing PEM fuell cell. Appl Energy 2013;109:60-6.

[48] Johansson KO, Head-Gordon MP, Schrader PE, Wilson KR, Michelson HA. Resonance-stabilized hydrocarbon-radical chain reactions may explain soot inception and growth. Science 2018;361:997-1000. 